\title{
Endotoxin Administration to Humans Inhibits Hepatic Cytochrome P450-mediated Drug Metabolism
}

\author{
Steven I. Shedlofsky, ${ }^{\star}$ Beth C. Israel, ${ }^{\ddagger}$ Craig J. McClain, ${ }^{\star \S}$ Daniell B. Hill, ${ }^{\star \S}$ and Robert A. Blouin ${ }^{\ddagger}$ \\ *Department of Medicine, VA Hospital and Division of Digestive Diseases, University of Kentucky College of Medicine; \\ ${ }^{\ddagger}$ University of Kentucky College of Pharmacy; and ${ }^{\S}$ General Clinical Research Center, University of Kentucky College of Medicine, \\ Lexington, Kentucky, 40511
}

\begin{abstract}
In experimental animals, injection of gram-negative endotoxin (LPS) decreases hepatic cytochrome P450-mediated drug metabolism. To evaluate this phenomenon in a human model of gram-negative sepsis, LPS was administered on two consecutive days to healthy male volunteers during which time a cocktail of antipyrine (AP-250 mg), hexobarbital (HB-500 mg), and theophylline (TH-150 mg) was ingested and the apparent oral clearance of each drug determined. Each subject had a control drug clearance study with saline injections. In the first experiment, six subjects received the drug cocktail $0.5 \mathrm{~h}$ after the first dose of LPS. In the second experiment, another six subjects received the drug cocktail $0.5 \mathrm{~h}$ after the second dose of LPS. In both experiments, LPS caused the expected physiologic responses of inflammation including fever with increases in serum concentrations of TNF $\alpha$, IL-1 $\beta$, IL-6, and acute phase reactants. In the first experiment, only minor decreases in clearances of the probe drugs were observed (7-12\%). However in the second experiment, marked decreases in the clearances of AP (35, 95\% CI 18-48\%), HB (27, 95\% CI 14-34\%), and TH (22, 95\% CI 12-32\%) were seen. The decreases in AP clearance correlated with initial peak values of TNF $\alpha(r=0.82)$ and IL-6 $(r=0.86)$. These data show that in humans the inflammatory response to even a very low dose of LPS significantly decreases hepatic cytochrome P450-mediated drug metabolism and this effect evolves over a $24-\mathrm{h}$ period. It is likely that septic patients with much higher exposures to LPS have more profound inhibition of drug metabolism. ( $J$. Clin. Invest. 1994. 94:2209-2214.) Key words: cytokines • inflammation - sepsis • tumor necrosis factor • lipopolysaccharide
\end{abstract}

\section{Introduction}

Gram-negative bacterial sepsis is still an important cause of morbidity and mortality $(1,2)$. Animal studies of sepsis using endotoxin (LPS) to elicit the inflammatory response have demonstrated that there are profound decreases in hepatic cytochrome P450-mediated drug metabolism (3-8). These decreases may be mediated by inflammatory cytokines such as interleukin-1 (9-11), tumor necrosis factor (11-14), and possi-

Address correspondence to Steven I. Shedlofsky, M.D., Department of Medicine (111), VA Hospital, Cooper Drive, Lexington, KY 40511.

Received for publication 28 March 1994 and in revised form 5 August 1994.

The Journal of Clinical Investigation, Inc.

Volume 94, December 1994, 2209-2214 bly interleukin-6 $(14,15)$. Whether decreases in hepatic P450mediated drug metabolism occur in humans with sepsis is not known, but is likely. Since critically ill septic patients are often given therapeutic drugs that require $\mathrm{P} 450$-mediated metabolism, adverse effects of these drugs may be a common but unrecognized problem.

Studying hepatic drug metabolism in septic patients is hampered by the inability to control for most of the variables that affect regulation of the cytochromes $\mathrm{P} 450$, including smoking status (16), diet (17), and concurrent medication use that could induce or inhibit various P450 isozymes. Another method to study effects of the inflammatory response on drug metabolism is to administer purified LPS to human volunteers and measure clearances of probe drugs. LPS administration to volunteers has been performed in a number of recent studies describing the physiologic responses of sepsis (18-22). In the current study, male volunteers ingested a "cocktail" of three probe drugs including antipyrine (AP), ${ }^{1}$ hexobarbital (HB), and theophylline (TH) $(23,24)$ whose clearances were measured on one occasion after saline injections and on another occasion after two LPS injections. This study demonstrates that even the relatively minor inflammatory response that occurred after this small dose of LPS was enough to decrease clearances of the probe drugs by $22-35 \%$.

\section{Methods}

12 male volunteers aged $21-42$ yr were enrolled in this study which was approved by the University of Kentucky Institutional Review Board and the General Clinical Research Center. Written consent was obtained at enrollment. All subjects were healthy as confirmed by medical history, physical exam, blood chemistries, urinalysis, and EKG. Subjects were nonsmokers and received no caffeine, theophylline products, nonsteroidal anti-inflammatory drugs, or other medications for at least $3 \mathrm{~d}$ before the study. All clearance studies were conducted in the General Clinical Research Center.

Each subject underwent two separate clearance studies: one with saline as a control and the other with LPS treatment. Half the subjects received LPS in the initial clearance study followed by the saline control study at least 2 wk later. For each clearance study, AP $(250 \mathrm{mg})$, HB (500 mg), and TH $(150 \mathrm{mg})$ were given as a "cocktail" $(23,24)$ after an overnight fast. For the LPS drug clearance study, each subject received two i.v. doses of U.S. FDA Bureau of Biologics endotoxin (LPS) (Lot EC-5, 20 Endotoxin U/kg) on consecutive mornings. Two experiments were conducted with six subjects in each. In the first experiment (EXP 1) LPS was administered $0.5 \mathrm{~h}$ before the drug cocktail and again $24 \mathrm{~h}$ later. Blood was collected at $0,10,20,30,45 \mathrm{~min}$ and 1, 2, 3, 4, $6,9,12,30$, and $48 \mathrm{~h}$ after the drug cocktail for plasma drug concentra-

\footnotetext{
'Abbreviations used in this paper: AGP, $\alpha_{1}$-acid glycoprotein; AP, antipyrine; C-RP, C-reactive protein; HB, hexobarbital; TH theophylline.
} 
tions and at various time points for plasma cytokine and serum acute phase reactant determinations. In the second experiment (EXP 2), both doses of LPS were given before the drug cocktail, (24.5 and $0.5 \mathrm{~h}$ before). Blood samples were drawn at various time points after the LPS and at the same times as above after the drug cocktail. Blood for complete blood count and clinical chemistry screen was collected prior to both drug clearance studies and $48 \mathrm{~h}$ after the first dose of LPS in EXP 1 and $72 \mathrm{~h}$ after the first dose of LPS in EXP 2.

Plasma concentrations of the cytokines TNF $\alpha$, interleukin-1 $\beta$ (IL1), and interleukin-6 (IL-6) were determined by commercial kits (Quantikine; R\&D Systems, Minneapolis, $M N$ ) and the acute phase reactants C-reactive protein (C-RP) and $\alpha_{1}$-acid glycoprotein (AGP) were determined in serum by commercial kits (Behring Diagnostic Incorporated, Somerville, NJ). Plasma AP, HB, and TH were analyzed as described previously (25).

$\mathrm{AP}, \mathrm{HB}$, and TH plasma concentration versus time data for each clearance study were analyzed by a nonlinear least squares regression analysis program (R-STRIP ${ }^{\circledR}$; Micromath Scientific Software, Salt Lake City, UT). Inspection of the log plasma concentration vs. time curves for each of the drug probes in both saline and LPS drug clearance studies showed monoexponential slopes for the elimination of each compound. This allowed assumption of a one-compartment model with first order absorption and elimination rate constants. Area under the concentration time curve (AUC) was calculated by the trapezoidal rule from zero to the last time point and then extrapolated to infinity using the following formula: $\mathrm{C}_{\text {last }} / \mathrm{K}$ where $\mathrm{C}_{\text {last }}$ is the last measured concentration time point and $\mathrm{K}$ is the terminal elimination rate constant obtained from R-STRIP ${ }^{\circledR}$. Oral clearance $\left(\mathrm{CL}_{\mathrm{o}}\right)$ of drug was defined as: $\mathrm{CL}_{\mathrm{o}}$ $=$ ORAL DOSE/AUC and calculated as such.

Statistical analysis. It was assumed that a $30 \%$ change in drug clearance would be clinically significant and a power analysis was performed using the known intra-individual coefficient of variation (6.8$8.2 \%$ ) from previous clearance studies for antipyrine (26) and determined that an $n=6$ was sufficient to detect this change. A statistical package (Pharmaceutical Calculation System, Springer-Verlag, NY) was used for data calculations. Drug clearance data between groups (saline control and LPS) were analyzed by the sign test (27). Confidence intervals for the changes in drug clearances were determined at the $95 \%$ level. Changes in peak plasma cytokines, peak serum acute phase proteins,

Table I. Clinical Characteristics and Laboratory Findings

\begin{tabular}{lccccc}
\hline & \multicolumn{2}{c}{ Experiment-1 $(n=6)$} & & \multicolumn{2}{c}{ Experiment-2 $(n=6)$} \\
\cline { 2 - 3 } \cline { 5 - 6 } & Baseline & LPS & & Baseline & LPS \\
\hline Temperature (oF) & $96.8 \pm 0.3$ & $99.8 \pm 1.0^{*}$ & & $97.3 \pm 1.0$ & $100.6 \pm 1^{*}$ \\
Pulse (bpm) & $63 \pm 1$ & $87 \pm 7^{*}$ & & $63 \pm 9$ & $91 \pm 11^{*}$ \\
Hematocrit $(\%)$ & $43.9 \pm 2.7$ & $42.0 \pm 2.3$ & & $46.5 \pm 1.6$ & $43.0 \pm 2.2$ \\
WBC $(\times 103 / \mu \mathrm{l})$ & $5.2 \pm 0.5$ & $5.1 \pm 0.5$ & & $5.8 \pm 1.2$ & $5.1 \pm 1.5$ \\
Platelets $(\times 103 / \mu \mathrm{l})$ & $228 \pm 49$ & $203 \pm 43$ & & $224 \pm 70$ & $192 \pm 40$ \\
Albumin $(\mathrm{g} / \mathrm{dl})$ & $3.7 \pm 0.2$ & $3.6 \pm 0.3$ & & $4.3 \pm 0.3$ & $3.9 \pm 0.3 *$ \\
ALT $(\mathrm{IU} / \mathrm{l})$ & $25 \pm 11$ & $33 \pm 21$ & & $24 \pm 7$ & $30 \pm 22$ \\
Alk. Phos. $(\mathrm{IU} / \mathrm{l})$ & $71 \pm 19$ & $67 \pm 18$ & & $83 \pm 35$ & $76 \pm 23$ \\
Total Bili $(\mathrm{mg} / \mathrm{dl})$ & $0.7 \pm 0.5$ & $0.6 \pm 0.3$ & & $0.7 \pm 0.2$ & $0.5 \pm 0.2$ \\
& & & & &
\end{tabular}

In experiment- 1 , the drug cocktail was given $0.5 \mathrm{~h}$ after the first dose of LPS and in experiment-2, the drug cocktail was given $0.5 \mathrm{~h}$ after the second dose of LPS. Peak temperatures and pulses were recorded 2.5 $h$ after the first dose of LPS administration in each experiment and compared with baseline values just before injection. Similar responses were seen after the second dose of endotoxin. For blood values reported, samples were taken $48 \mathrm{~h}$ after the first dose of LPS in EXP-1 and 72 $h$ after the first dose of LPS in EXP-2 and compared with baseline values obtained at enrollment in the study. Data are means \pm SD and $* P$ $<0.05$ for LPS compared with baseline.
Table II. Serum Inflammatory Responses and Changes in Drug Clearance after LPS in Experiment-1

\begin{tabular}{lccc}
\hline \multicolumn{1}{c}{ Serum markers } & $\begin{array}{c}\text { Saline } \\
\text { control }\end{array}$ & $\begin{array}{c}\text { LPS } \\
\text { Day 1 }\end{array}$ & $\begin{array}{c}\text { LPS } \\
\text { Day } 2\end{array}$ \\
\hline TNF $(\mathrm{pg} / \mathrm{ml})$ & $4 \pm 1$ & $53 \pm 34^{*}$ & $19 \pm 11^{*}$ \\
IL-6 $(\mathrm{pg} / \mathrm{ml})$ & $3 \pm 1$ & $31 \pm 36$ & $52 \pm 58$ \\
C-RP $(\mathrm{mg} / \mathrm{dl})$ & $0 \pm 0$ & $2.7 \pm 0.5^{*}$ & $3.3 \pm 0.5^{*}$ \\
AGP $(\mathrm{mg} / \mathrm{dl})$ & $71 \pm 21$ & $89 \pm 15^{*}$ & $100 \pm 15^{*}$ \\
& & & Percent \\
& & & LPS \\
Drug clearance data & Saline & $2.06 \pm 0.40$ & $12 \%$ \\
Antipyrine $(1 / \mathrm{h})$ & $2.33 \pm 0.43$ & $17.9 \pm 4.2$ & $8 \%$ \\
Hexobarbital $(1 / \mathrm{h})$ & $19.5 \pm 5.8$ & $3.08 \pm 0.60$ & $7 \%$ \\
Theophylline $(\mathrm{l} / \mathrm{h})$ & $3.30 \pm 0.33$ & & \\
\hline
\end{tabular}

TNF peaked $1.5 \mathrm{~h}$ after LPS on each day, IL-6 peaked $4 \mathrm{~h}$ after LPS after the first LPS dose and $2 \mathrm{~h}$ after the second dose. There were no peaks with saline. CRP and AGP were measured $24 \mathrm{~h}$ after saline and at 24 and $48 \mathrm{~h}$ after the first dose of LPS. In this experiment (EXP 1) the drug cocktail was administered $0.5 \mathrm{~h}$ after the first dose of endotoxin or saline. Blood was collected over $48 \mathrm{~h}$ and clearance values were determined. Data are means \pm SD for six subjects. $* P<0.05$ for LPS vs. saline.

bilirubin, albumin, white blood cell count, liver enzymes, temperature, and heart rate were analyzed by paired Student's $t$ test. The relationship between alterations in drug clearances caused by LPS with changes in plasma cytokines and acute phase proteins were correlated to assess a statistical association using regression analysis and $F$ test. Statistical significance was defined as $P<0.05$ for all tests.

\section{Results}

As shown in Table I, endotoxin administration caused physical signs consistent with inflammation, but no obvious evidence of hepatic damage. After each dose of endotoxin, but not saline, subjects from both experiments experienced significant elevations in temperature and pulse, along with clinical symptoms of chills, malaise, and headache. No changes in white blood cell count, platelet counts, liver alanine aminotransferase, alkaline phosphatase, or total bilirubin were observed. There were minor but not significant decreases in subjects' hematocrits, most likely due to the volume of blood drawn, and there was a minor but statistically significant decrease in albumin concentrations in EXP 2 but not EXP 1 .

In EXP 1, (drug cocktail given $0.5 \mathrm{~h}$ after the first dose of LPS in six subjects), a number of biochemical indicators documented that an inflammatory response was elicited. As shown in Table II, there were marked increases in concentrations of the cytokines TNF (peaking at $90 \mathrm{~min}$ ) and IL-6 (peaking at $4 \mathrm{~h}$ ) after the first dose of LPS. After the second dose of LPS the next morning, the TNF peaks were lower, but the IL6 responses were not blunted (higher in three subjects and only slightly lower in the others) and IL-6 peaked slightly earlier, just $2 \mathrm{~h}$ after the LPS. Data for IL- $\beta$ are not shown. Although some IL- $1 \beta$ determinations were made, this cytokine peaked at $9 \mathrm{~h}$ in several patients $(1.5 \mathrm{pg} / \mathrm{ml}$ at baseline rising to $15 \mathrm{pg} /$ $\mathrm{ml}$ ) after the first dose of LPS, but samples from this time point were not available for three subjects and unavailable for all subjects after the second LPS dose. Both of the acute phase 
reactants C-RP and AGP demonstrated consistent increases after each dose of LPS.

Despite eliciting an inflammatory response, drug clearance values for all three probe drugs showed only modest decreases of $7-12 \%$, none of which were statistically significant by the sign test (Table II). However, studies in experimental animals (7) have shown that maximal depression of P450 occurs 12$24 \mathrm{~h}$ after an LPS injection. We therefore predicted that decreases in drug clearances would be greater in EXP 2 in which both doses of LPS were administered before the drug "cocktail" ( 24.5 and $0.5 \mathrm{~h}$ before).

Fig. 1 illustrates the changes in plasma cytokines (TNF, IL-1 and IL-6) and serum acute phase proteins (C-RP, AGP) observed after the LPS or saline injections in EXP 2. Cytokines and acute phase proteins were markedly elevated after endotoxin administration when compared to control values (after saline). Concentrations of TNF (Fig. $1 a$ ) peaked within 90 min after each LPS injection, but the response to the second LPS dose was much less than the first. IL-1 $\beta$ (Fig. $1 b$ ) peaked $4-$ $6 \mathrm{~h}$ after the first dose, did not return to baseline, and then increased even further with the second LPS dose before returning to baseline at $48 \mathrm{~h}$. IL-6 (Fig. $1 \mathrm{c}$ ) peaked sharply $4 \mathrm{~h}$ after the first LPS dose, and had a much lower response after the second LPS dose. The C-RP and AGP responses again showed a steady increase after both doses of LPS. Values at 72 h (data not shown) were down slightly from $48 \mathrm{~h}$, but were well above baseline and saline levels.

In EXP 2 much larger and significant changes $(P<0.05)$ in drug clearances were apparent as shown in Fig. 2. There was a $35 \%$ decrease in AP clearance, (95\% CI, 18 to $48 \%$ ), a $27 \%$ decrease in HB clearance, (95\% CI, 14 to $34 \%$ ), and a $22 \%$ decrease in TH clearance ( $95 \% \mathrm{CI}, 12$ to $32 \%$ ). Correlations between the changes in drug clearances and LPS-induced cytokine and acute phase protein concentrations were examined. Although no statistically significant correlations were seen between any of the cytokine and acute phase protein responses and the decreases in $\mathrm{HB}$ and $\mathrm{TH}$ clearances, significant $(P$ $<0.05)$ associations were found for decreased AP clearance and the peak TNF $(r=.82)$ and peak IL-6 $(r=.86)$ concentrations seen after the first dose of LPS (Fig. 3). These were cytokine responses that had been elicited before the drug cocktail was administered. Correlations were not significant between IL- $1 \beta$ or acute phase protein responses and decreased AP clearances.

\section{Discussion}

Because of the well known inhibition of hepatic cytochrome P450-mediated drug metabolism during inflammation in animal studies $(3-8)$, it is very likely that similar inhibition occurs in humans. However, few studies evaluating regulation of P450 metabolism in critically ill septic patients have been performed despite the fact that these patients receive numerous drugs that require $\mathrm{P} 450$ for their clearances. Drug toxicities due to decreased clearance may be common but unrecognized phenomena that contribute to patient morbidity and mortality. Although Sangrador et al. reported in ICU patients a $34 \%$ decrease in $\mathrm{TH}$ clearance in one study (28) and a 50\% decrease in caffeine clearance in another study (29), inflammatory responses were not assessed.

There are many difficulties in studying P450 metabolism in critically ill patients, including an inability to control for such
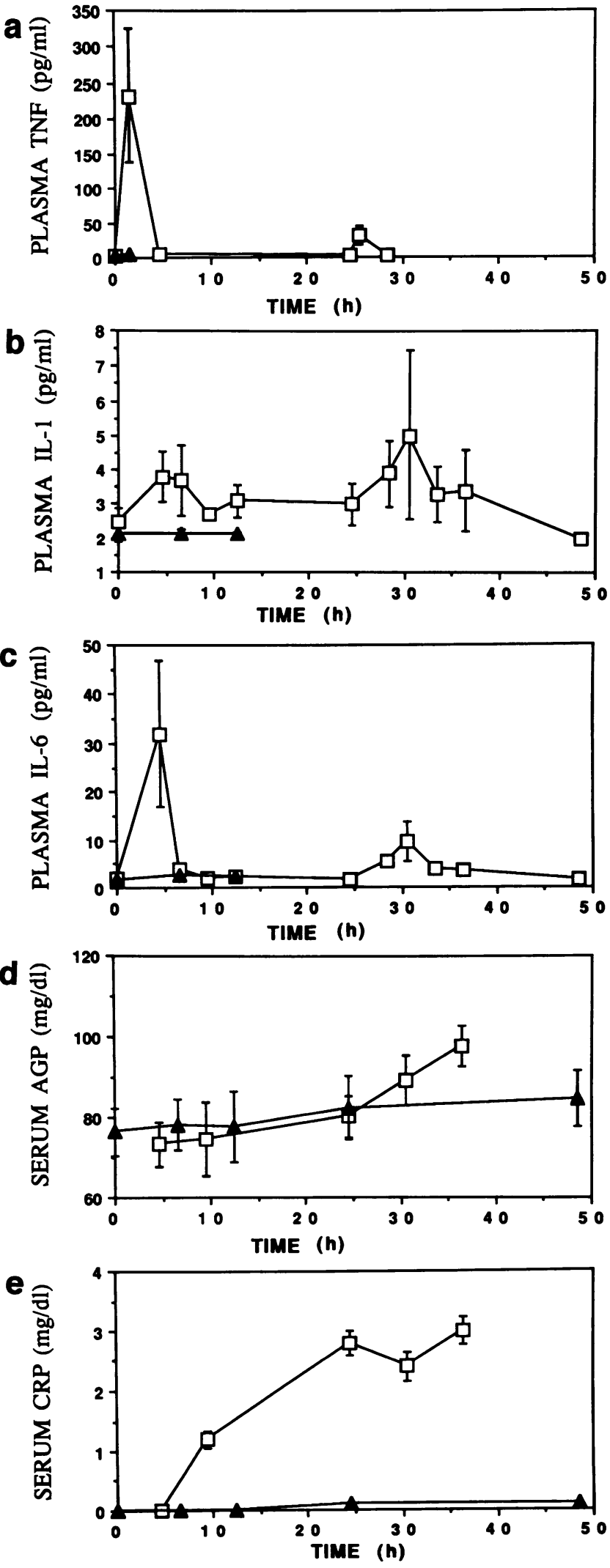

Figure 1. Plasma cytokine and serum acute phase reactant concentrations after LPS injections at 0 and $24 \mathrm{~h} \mathrm{( \square -}-\square)$ or after saline injections at same times $(\Delta-\longrightarrow \Delta)$. The drug cocktail was given at $24.5 \mathrm{~h}$. (a) Plasma tumor necrosis factor; (b) plasma interleukin-1 $\beta$; (c) plasma interleukin-6; $(d)$ serum $\alpha_{1}$-acid glycoprotein; and $(e)$ serum C-reactive protein. Each point is mean \pm SEM of six subjects. 

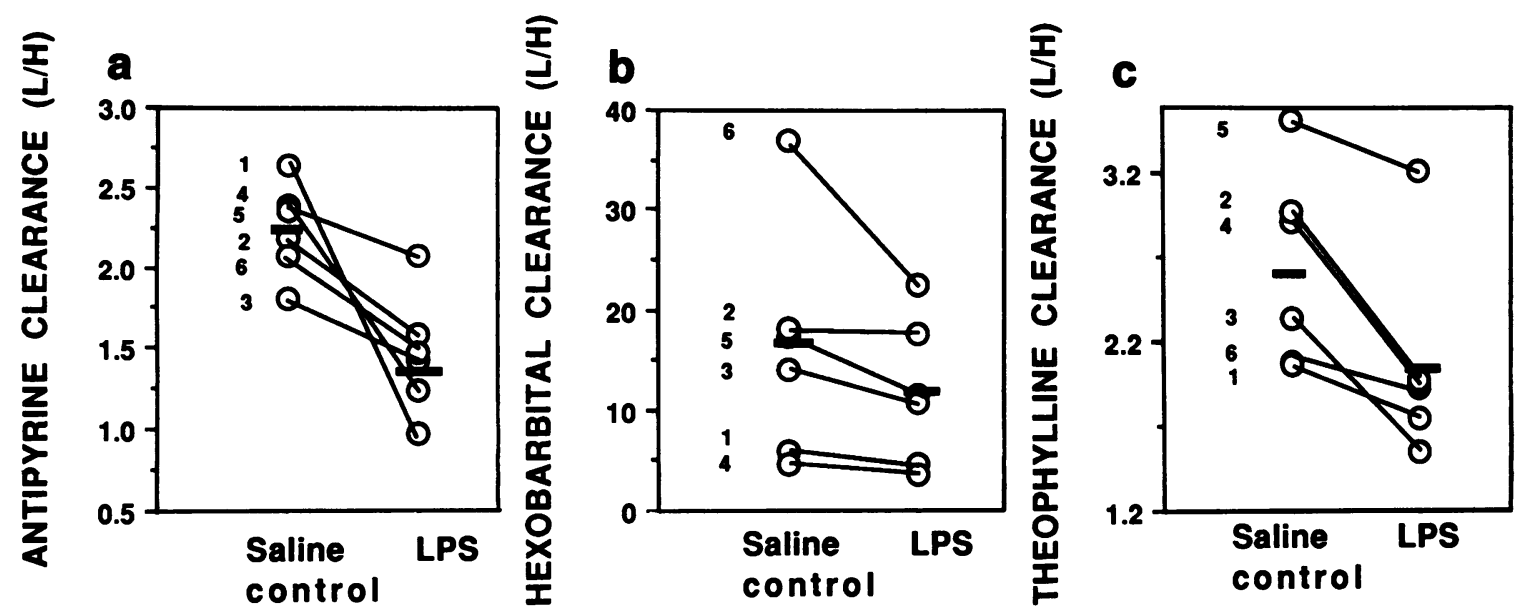

Figure 2. Oral drug clearances of antipyrine $(250 \mathrm{mg})$, hexobarbital $(500 \mathrm{mg})$, and theophylline $(150 \mathrm{mg})$ administered as a "cocktail" in six male subjects given on one occasion saline IV $0.5 \mathrm{~h}$ brfore the drugs and on another occasion LPS ( 20 endotoxin units IV) 24.5 and $0.5 \mathrm{~h}$ before the drugs (EXP 2). The numbers identify data for individual subjects for each drug clearance comparison. The bar is the arithmetic mean for clearance data.

factors as smoking, diet, concurrent drug use, and hemodynamic alterations (e.g., shock) that might alter hepatic blood flow and function. Administration of endotoxin (LPS) to human volun-

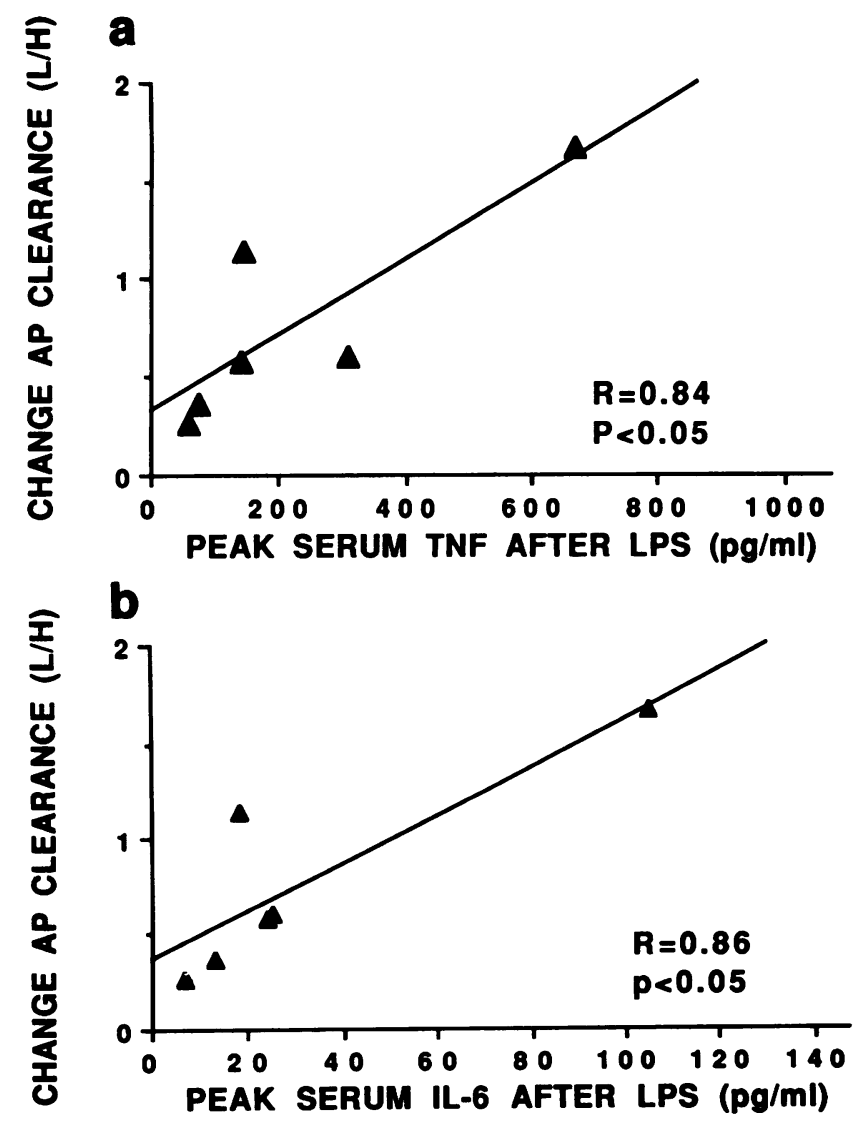

Figure 3. Regression analyses comparing the changes (decreases, liters/ h) in antipyrine (AP) clearance between saline control and LPS drug clearance studies and $(a)$ the peak tumor necrosis factor (TNF) or $(b)$ IL-6 plasma concentrations $(\mathrm{pg} / \mathrm{ml})$ after the first dose of LPS in each subject of EXP 2. teers offers a more controlled and reproducible model to study the effects of the inflammatory response on hepatic P450-mediated drug metabolism. Because volunteers are clinically stable, the clearances of drug probes can be analyzed over relatively prolonged periods of time (24-48 h), and several probes can be administered simultaneously using the cocktail approach. In the current study, each of the three drug probes used $(23,24)$ were chosen because their oral clearances are dependent on activities of one or more hepatic microsomal cytochromes P450 and not on hepatic blood flow (30). It is also unlikely that extrahepatic sites such as the lung or intestine play an important role in their clearances (24). Furthermore, because the intraindividual variation for measuring oral clearances is low (26), using each subject as his own control allowed the use of a relatively small number of subjects to achieve significant results.

The current study demonstrates unequivocally that LPS administration to male human volunteers depresses hepatic cytochrome P450-mediated drug metabolism. Decreased clearances of all three drugs used in this study were seen, (AP [35\%], HB [27\%], and TH [22\%]). Despite the very low LPS dose used (4 $\mathrm{ng} / \mathrm{Kg}$ or 20 "'endotoxin" $\mathrm{U} / \mathrm{Kg}$ ), these decreases are comparable to findings in most rodent studies $(3-8)$ where doses ranging from $30 \mathrm{mg}$ to $5 \mu \mathrm{g} / \mathrm{Kg}$ caused $35-50 \%$ decreases in total cytochromes $\mathrm{P} 450$ concentrations and various drug metabolizing activities in hepatic microsomes. Humans are known to be much more sensitive to LPS than rodents (31). However, because septic patients are probably exposed to much higher concentrations of LPS and suffer multisystem organ failure from these doses, it is likely that the decreases in P450-mediated metabolism reported in the volunteers are an underestimation of what occurs clinically.

The current study also assessed the timing of the inflammatory effect on depression of cytochrome P450-mediated drug metabolism. Drug clearances were not significantly depressed when the probe drugs were given just $0.5 \mathrm{~h}$ after the initial LPS exposure (EXP 1), but were significantly depressed when the probe drugs were administered $24 \mathrm{~h}$ later (EXP 2). Therefore, it is apparent that depression of drug metabolism in humans is not an immediate effect of the inflammatory response, but one 
which develops over a 24-h period. Based on data from animal experiments, maximal depression of cytochrome P450 concentrations and activities occurs from 18 to $24 \mathrm{~h}$ after a single dose of LPS with a gradual return to baseline values by $48-72 \mathrm{~h}(7)$.

In the current study, LPS administration elicited the expected cytokine and acute phase responses confirming previous reports (18-22) of a safe and well characterized inflammatory response with this dose of LPS. Clinical symptoms of malaise, chills, and headache occurred $\sim 1$ or $2 \mathrm{~h}$ after LPS injection followed by significant $(P<0.05)$ increases in temperature and heart rate lasting three to four hours. In EXP 1, the administration of the drug cocktail containing the anti-inflammatory drug antipyrine $(250 \mathrm{mg}) 0.5 \mathrm{~h}$ after the LPS did not mitigate these physiologic responses.

Based on animal studies (8-15), it is likely that depression of cytochrome P450-mediated drug metabolism after LPS is mediated by inflammatory cytokines, since administration of cytokines in these studies reproduced the depressions seen with LPS (8-15). Supporting this contention is our finding that the decreases in AP clearance in EXP 2 correlated with peak TNF and IL-6 responses after the first dose of LPS (Fig. 3, $a$ and $b$ ).

The current study administered a second LPS dose $24 \mathrm{~h}$ after the first in order to "maximize" the inflammatory response during the drug clearance studies. In EXP 1, (Table II) there did not appear to be any significant blunting of the response to the second LPS dose, a phenomenon referred to as "endotoxin tolerance"' (31). In EXP 2, in which the drug cocktail was given $0.5 \mathrm{~h}$ after the second LPS dose, there did appear to be marked blunting of the TNF and IL-6 responses (Figs. 1, $a$ and $c$ ). However, clinical symptoms were not blunted and because the drug cocktail could have affected the cytokine responses, this protocol doesn't allow one to address the issue of endotoxin tolerance. Tolerance to the effects of LPS in septic patients was recently addressed by Munoz et al. (32) and McCall et al. (33), and found to be very complex. Granowitz et al. (34) also reported that a single dose of LPS to male volunteers made their peripheral monocytes less responsive to subsequent stimulation in vitro. How LPS tolerance might relate to regulation of hepatic drug metabolism in humans is unknown, but animal studies by Williams (35), demonstrated that LPS tolerance also extends to effects on hepatic cytochromes P450.

Several animal studies have also addressed the issue of LPSinduced inflammation on specific $\mathrm{P} 450$ isoenzymes by assessing enzyme activities, specific $\mathrm{P} 450$ proteins and mRNA concentrations (6-8). Stanley et al. (6) observed differential inhibition of P450 isozyme expression in rats with low doses of LPS, whereas high doses of LPS depressed all isoenzymes studied. Morgan (8) recently reported decreased P450 2C6, 2C7, 2C11, $2 \mathrm{C} 12$, and $2 \mathrm{E} 1 \mathrm{mRNA}$ but decreased proteins for only $\mathrm{P} 450$ $2 \mathrm{C} 11,2 \mathrm{C} 12$, and $2 \mathrm{E} 1$ after LPS administration. Since P450 isoenzymes vary between species, how these studies apply to humans is not clear. The three probes used in the current study are rather "broad" substrates and are not believed to represent the activities of specific P450s, although the clearances of TH and HB provide assessments primarily of P450 1A2 and members of the P450 $2 \mathrm{C}$ family, respectively (36-41). Whether LPS-induced inflammation differentially affects different P450 isoenzymes in humans will have to await studies using more specific probes.

In conclusion, this study shows that LPS-induced inflammation in humans is associated with significant depression of hepatic cytochrome P450-mediated drug metabolism. The depression in drug metabolism takes several hours to develop after initiation of the inflammatory response and the extent of the depression correlates with the intensity of the inflammatory response as assessed by elevations of the cytokines TNF $\alpha$ and IL-6. Further use of this experimental model (injecting human volunteers with LPS) can yield information as to the significance of depressed hepatic drug metabolism in critically ill septic patients as well as which drug metabolizing enzymes are most affected.

\section{Acknowledgments}

The authors wish to thank the CRC staff, including Patti Nickl, Connie Mitchell, Amy Hughs, and Susan Berryman, and acknowledge the technical assistance of Drs. Alice Swim and Rajna Tosheva-Touanova and statistical review by Dr. Richard Kryscio.

This work was supported by the Department of Veterans Affairs and by a National Institutes of Health General Clinical Research Center grant M01RR02602-07.

\section{References}

1. Bone, R. C., C. J. Fisher, T. P. Clemmer, G. J. Slotman, C. A. Metz, R. A. Balk, and The Methylprednisolone Severe Sepsis Study Group. 1987. A controlled clinical trial of high-dose methylprednisolone in the treatment of severe sepsis and septic shock. N. Engl. J. Med. 317:653-658.

2. Danner, R. L., R. J. Elin, J. M. Hosseini, R. A. Wesley, J. M. Reilly, and J. E. Parrillo. 1991. Endotoxemia in human septic shock. Chest. 99:169-175.

3. Gorodischer, R., J. Krasner, J. J. McDevitt, J. P. Nolan, and S. J. Yaffee. 1976. Hepatic microsomal drug metabolism after administration of endotoxin in rats. Biochem. Pharmacol. 25:351-353.

4. Williams, J. F., S. Lowitt, and A. Szentivanyi. 1980. Endotoxin depression of hepatic mixed function oxidase system in $\mathrm{C} 3 \mathrm{H} / \mathrm{HeJ}$ and $\mathrm{C} 3 \mathrm{H} / \mathrm{HeN}$ mice. Immunopharmacol. 2:285-291.

5. Kasai, N., and K. Egawa. 1985. Effect of endotoxin on cytochrome P-450 activity. In Handbook of Endotoxin, Vol. 3. Cellular Biology of Endotoxin. L. J. Berry, editor. Elsevier B.V. 185-198.

6. Stanley, L. A., D. J. Adams, R. Lindsay, R. R. Meehan, W. Liao, and C. R. Wolf. 1988. Potentiation and suppression of mouse liver cytochrome P-450 isozymes during the acute-phase response induced by bacterial endotoxin. Eur. J. Biochem. 174:31-36.

7. Morgan, E. T. 1989. Suppression of constitutive cytochrome P-450 gene expression in livers of rats undergoing an acute phase response to endotoxin. $\mathrm{Mol}$. Pharmacol. 36:699-707.

8. Morgan, E. T. 1993. Down-regulation of multiple cytochrome P450 geneproducts by inflammatory mediators in vivo. Biochem. Pharmacol. 45:415-419.

9. Ghezzi, P., B. Saccardo, P. Villa, V. Rossi, M. Bianchi, and C. Dinarello. 1986. Role of interleukin-1 in the depression of liver drug metabolism by endotoxin. Infect. Immun. 54:837-840.

10. Shedlofsky, S. I., A. T. Swim, J. M. Robinson, V. S. Gallicchio, D. A. Cohen, and C. J. McClain. 1987. Interleukin-1 (IL-1) depresses cytochrome P450 levels and activities in mice. Life Sci. 40:2331-2336.

11. Bertini, R., M. Bianchi, P. Villa, and P. Ghezzi. 1988. Depression of liver drug metabolism and increase in plasma fibrinogen by interleukin-1 and tumor necrosis factor: a comparison with lymphotoxin and interferon. Int. J. Immunopharmacol. 10:525-530.

12. Ghezzi, P., B. Saccardo, and M. Bianchi. 1986. Recombinant tumor necrosis factor depresses cytochrome P-450-dependent microsomal drug metabolism in mice. Biochem. Biophys. Res. Commun. 136:316-321.

13. Bertini, R., M. Bianchi, A. Erroi, P. Villa, and P. Ghezzi. 1989. Dexamethasone modulation of in vivo effects of endotoxin, tumor necrosis factor, and interleukin-1 on liver cytochrome P-450, plasma fibrinogen, and serum iron. $J$. Leukocyte Biol. 46:354-262.

14. Wright, K., and E. T. Morgan. 1991. Regulation of cytochrome P-450IIC12 expression by interleukin-1 $\alpha$, interleukin-6, and dexamethasone. Mol. Pharmacol. 39:468-474.

15. Chen, Y. L., I. Florentin, A. M. Batt, L. Ferrari, J. P. Giroud, and L. Chauvelot-Moachon. 1992. Effects of interleukin-6 on cytochrome P450-dependent mixed function oxidases in the rat. Biochem. Pharmacol. 44:137-148.

16. Vahakangas, K., O. Pelkonen, and E. Sotaniemi 1983. Cigarette smoking and drug metabolism. Clin. Pharmacol. \& Ther. 33:375-380.

17. Kappas, A., K. E. Anderson, A. H. Conney, and A. P. Alvares. 1976. 
Influence of dietary protein and carbohydrate on antipyrine and theophylline metabolism in man. Clin. Pharmacol. \& Ther. 20:643-653.

18. Moore, F. D., Jr., N. A. Moss, A. Revhaug, D. Wilmore, J. A. Mannick, and M. L. Rodrick. 1987. A single dose of endotoxin activates neutrophils without activating complement. Surgery. 102:200-205.

19. Hesse, D. G., K. J. Tracey, Y. Fong, K. R. Manogue, M. A. Palladino, Jr., A. Cerami, and G. T. Shires. 1988. Cytokine appearance in human endotoxemia and primate bactermia. Surg. Gynecol. \& Obstet. 166:147-153.

20. Michie, H. R., K. R. Manogue, D. R. Spriggs, A. Revhaug, S. O'Dwyer, C. A. Dinarello, A. Cerami, S. M. Wolff, and D. W. Wilmore. 1988. Detection of circulating tumor necrosis factor after endotoxin administration. N. Engl. J. Med. 318:1481-1486.

21. Suffredini, A. F., R. E. Fromm, N. M Parker, M. Brenner, J. A. Kovacs, R. A. Wesley, and J. E. Parrillo. 1989. The cardiovascular response of normal humans to the administration of endotoxin. N. Engl. J. Med. 321:280-287.

22. Spinas, G. A., U. Keller, and M. Brockhaus. 1992. Release of soluble receptors for tumor necrosis factor (TNF) in relation to circulating TNF during experimental endotoxemia. J. Clin. Invest. 90:533-536.

23. Schellens, J. H. M., J. H. F. VanDerWart, M. Danhof, E. A. VanDerVelde, and D. D. Breimer. 1988. Relationship between the metabolism of antipyrine hexobarbitone and theophylline in man as assessed by a "cocktail" approach Br. J. Clin. Pharmacol. 26:373-384.

24. Schellens, J. H. M., A. R. Janssens, J. H. F. VanDerWart, E. A. VanDerVelde, and D. D. Breimer. 1989. Relationship between the metabolism of antipyrine, hexobarbital and theophylline in patients with liver disease as assessed by a "cocktail" approach. Eur. J. Clin. Invest. 19:472-479.

25. Israel, B. C., R. A. Blouin, W. McIntyre, and S. I. Shedlofsky. 1993 Effects of interferon- $\alpha$ monotherapy on hepatic drug metabolism in cancer patients. Br. J. Clin. Pharmacol. 36:229-235.

26. Elin, R. J., E. S. Vesell, and S. M. Wolff. 1975. Effects of etiocholanoloneinduced fever on plasma antipyrine half-lives and metabolic clearance. Clin. Phar mol. \& Ther. 17:447-457.

27. Bolton, S. 1990. Pharmaceutical Statistics: Practical and Clinical Applications. Marcel Dekker Inc., New York. 496-498.

28. Sangrador, G., A. Sanchez-Alcaraz, R. Ubeda, and P. Ibanez. 1990. Theophylline plasma clearance in critically ill geriatric patients receiving total parenteral nutrition and in control patients. J. Clin. Pharm. Ther. 15:273-278.

29. Sanchez-Alcaraz, A., P. Ibanez, and G. Sangrador. 1991. Pharmacokinetics of intravenous caffeine in critically ill patients. J. Clin. Pharm. Ther. 16:285289.
30. Wilkinson, G. R., and D. G. Shand. 1975. A physiologic approach to hepatic drug clearance. Clin. Pharmacol. \& Ther. 18:377-390

31. Greisman, S. E., and R. B. Hornick. 1973. Mechanisms of endotoxin tolerance with special reference to man. J. Infect. Dis. 128:S265-S276.

32. Munoz, C., J. Carlet, C. Fitting, B. Misset, J.-P. Bieriot, and J.-M. Cavaillon. 1991. Dysregulation of in vitro cytokine production by monocytes during sepsis. J. Clin. Invest. 88:1747-1754.

33. McCall, C. E., L. M. Grosso-Wilmoth, K. LaRue, R. N. Guzman, and S. L. Cousart. 1993. Tolerance to endotoxin-induced expression of the interleukin$1 \beta$ gene in blood neutrophils of humans with the sepsis syndrome. J. Clin. Invest. 91:853-861.

34. Granowitz, E. V., R. Porat, J. W. Mier, S. F. Orencole, G. Kaplanski, E. A. Lynch, K. Ye, E. Vannier, S. M. Wolff, and C. A. Dinarello. 1993. Intravenous endotoxin suppresses the cytokine response of peripheral blood mononuclear cells of healthy humans. J. Immunol. 151:1637-1645.

35. Williams, J. F. 1985. Induction of tolerance in mice and rats to the effect of endotoxin to decrease the hepatic microsomal mixed-function oxidase system. Evidence for a possible macrophage-derived factor in the endotoxin effect. Int. J. Immounopharmacol. 7:501-509.

36. Robson, R. A., J. O. Miners, A. P. Matthews, I. Stupans, D. Meller, M. E. McManus, and D. J. Birkett. 1988. Characterisation of theophylline metabolism by human liver microsomes: Inhibition and immunochemical studies. Biochem. Pharmacol. 37:1651-1659.

37. Fuhr, U., J. Doehmer, N. Battula, C. Wolfel, C. Kudla, Y. Keita, and A. H. Staib. 1992. Biotransformation of caffeine and theophylline in mammalian cell lines genetically engineered for expression of single cytochrome P450 isoforms. Biochem. Pharmacol. 43:225-235.

38. Sarkar, M., C. Hunt, P. S. Guzelian, and H. T. Karnes. 1992. Characterization of human liver cytochromes P-450 involved in theophylline metabolism. Drug Metab. Dispos. 20:31-37.

39. Loft, S. 1990. Metronidazole and antipyrine as probes for the study of foreign compound metabolism. Pharmacol. Toxicol. 66 Suppl 6:1-31.

40. Knodell, R. G., R. K. Dubey, G. R. Wilkinson, and F. P. Guengerich 1988. Oxidative metabolism of hexobarbital in human liver: relationship to polymorphic S-mephenytoin 4-hydroxylation. J. Pharmacol. Exp. Ther. 245:845-849.

41. Brian, W., P. K. Srivastava, D. R. Umbenhauer, R. S. LLoyd, and F. P. Guengerich. 1989. Expression of human liver cytochrome P450 protein with tolbutamide hydroxylase activity in Saccharomyces. Biochemistry. 28:49934999. 